\title{
Avaliação do crescimento, desenvolvimento e produção do algodão irrigado com água de esgotos sanitários tratados
}

\author{
Joseilton dos Santos Nascimento ${ }^{1}$, Tancredo Augusto Souza ${ }^{1 *}$, José Fideles Filho ${ }^{1}$, Raphael Moreira Beirigo ${ }^{1}$
}

RESUMO: A escassez dos recursos hídricos vem se tornando um fator agravante na irrigação de culturas agrícolas, com isso a utilização de agua residuária tratada surge como uma alternativa viável para suprir essa demanda. O presente trabalho teve como objetivo avaliar o efeito da utilização de águas residuária na cultura do algodoeiro. A pesquisa foi realizada na Estação Experimental de Tratamentos Biológicos de Esgotos Sanitários - EXTRABES, no município de Campina Grande-PB, em delineamento casualizado com cinco tratamentos e quatro repetições. Onde o tratamento 1 (T1) - irrigação com água de abastecimento proveniente da CAGEPA; tratamento 2 (T2) - irrigação com o efluente proveniente do reator UASB; tratamento 3(T3) - irrigação com efluente proveniente do filtro em série; tratamento 4 (T4) - irrigação com o efluente proveniente do filtro anaeróbio; tratamento 5 (T5) - irrigação com o efluente proveniente da lagoa de macrófitos. Os resultados foram submetidos à análise de variância (teste F) e as médias foram comparadas pelo teste de Tukey com 5\% de probabilidade. A aplicação de água residuária via irrigação na cultura do algodão proveniente do reator UASB e filtro em série aumentaram as concentrações de fosforo, potássio e matéria orgânica na camada superficial do solo.

Palavras-chave: água residuária, fertirrigação, Gossipium hisurtam. L.

\section{Evaluation of the growth, development and production of cotton irrigated with treated sanitary sewage}

\begin{abstract}
The scarcity of water resources has become an aggravating factor in the irrigation of agricultural crops, with the use of treated wastewater as a viable alternative to meet this demand. The present study had as objective to evaluate the effect of the use of wastewater in the cotton crop. The research was fulfilled out in the Experimental Station of Biological Treatments of Sanitary Sewage - EXTRABES, in the city of Campina Grande-PB, in a randomized design with five treatments and four replications. Where treatment 1 (T1) - irrigation with water supply from CAGEPA; treatment 2 (T2) - irrigation with the effluent from the UASB reactor; treatment 3 (T3) - irrigation with effluent from the filter in series; treatment 4 (T4) - irrigation with the effluent from the anaerobic filter; treatment 5 (T5) - irrigation with effluent from the macrophyte lagoon. The results were submitted to analysis of variance (test F) and the means were compared by the Tukey test with $5 \%$ probability. The application of wastewater through irrigation in the cotton crop from the UASB reactor and filter in series increased the concentrations of phosphorus, potassium and organic matter in the surface layer of the soil.
\end{abstract}

Keywords: wastewater, fertirrigation, Gossipium hisurtam. L

\section{INTRODUÇÃO}

A tecnologia de energia renovável baseada em energia solar foi utilizada recentemente para tratamento de águas residuárias para irrigação de culturas agrícolas, proporcionando alta qualidade para o crescimento de culturas hortícolas e fruteiras (INTRIAGO et al., 2018). A utilização da água residuária proporciona efeitos positivos nas variáveis de crescimento e produção da cultura do algodoeiro, podem representar uma tecnologia social importante e com capacidade para potencializar a produção agrícola da região semiárida, contribuindo com alternativas para transformar os resíduos líquidos em fonte de renda para as comunidades, além de indicar meios para mitigar e diminuir o impacto socioambiental causado por esses agentes de origem doméstica (GARCIA, PARGAMENT, 2015; CHOWDHURY et al., 2014; GANJEGUNTE et al., 2017).

Nas águas residuárias domésticas, encontram-se os diferentes organismos patogênicos e em elevadas concentrações, com isso a utilização de esgotos domésticos para irrigação de culturas agrícolas necessita de adequado e eficiente tratamento, para evitar riscos ao meio ambiente e, sobretudo, à saúde dos consumidores pela possibilidade de contaminações microbiológicas (INTRIAGO et al., 2018; EL MOUSSAOUI et al., 2017). A busca por alternativas racionais que viabilizem o uso de águas residuárias se faz a cada dia mais necessário, tanto do ponto de vista ambiental como do ponto de vista econômico, sobretudo em regiões áridas e

Recebido em 24/10/2018; Aceito para publicação em 25/02/2018

${ }^{1}$ Universidade Federal da paraíba

*E-mail: tancredo_agro@ hotmail.com 
semiáridas onde os recursos hídricos são bastante escassos, que frequentemente são assolados por longos períodos de estiagens e secas quase periódicas (WOLTERSDORF e al., 2018; REZNIK et al., 2017).

A utilização de águas de esgotos sanitários tratados na agricultura fornece nutrientes que são utilizados pelas plantas, possibilitando assim, a substituição total ou parcial de fertilizantes químicos. Bedbadis et al. (2015), ressaltam a importância da utilização de águas residuárias domésticas para o fornecimento de nutrientes e aumento de produção. Ao aplicarem esgoto residencial tratado na cultura da oliveira, obtiveram um aumento de 40,7\% na produção. Ben et al. (2018) concluíram que o uso de água residuária proporcionou alto rendimento e boa qualidade em, além de ter diminuído as quantidades de fertilizantes à base de nitrogênio e fósforo.

A reutilização da água doméstica tem sido maciça e hoje Israel reutiliza $75 \%$ dos efluentes gerados, contra 14\% na Espanha, 9\% na Austrália, $8 \%$ na Itália, $5 \%$ na Grécia e menos de $1 \%$ na Europa (JUANICÓ, 2007). Portanto, a prática do reuso de águas domésticas tratadas tem papel fundamental no planejamento e na gestão sustentável dos recursos hídricos, podendo ser potencialmente utilizada em regiões áridas e semiáridas (EL MOUSSAOUI et al., 2017; SAID INES, MUSCOLO, 2016). O uso de águas residuárias na agricultura vem sendo uma alternativa potencial, pela grande quantidade de água residuária ofertada durante todo o ano, garantindo economia de água, com isso há possibilidade de aumento na produção das culturas irrigadas, pela expansão das áreas agrícolas e possibilidade de aumenta o valor agregado do produto com a diminuição dos custos de produção com irrigação e fertilizantes (GATTA et.al., 2016; BARBOSA, et al., 2015; WIELEMAKER et al., 2018). Com isso, o uso de águas residuárias na agricultura é uma forma alternativa para suprir a escassez de água e fornecer nutrientes para as culturas agrícolas.

Diversos estudos se concentraram nos efeitos da irrigação com efluentes domésticos tratados na cultura do algodão. (SOUSA NETO et al., 2012; USEN et al., 2016; FIGUEIREDO et al., 2012) O reuso da água residuária na cultura do algodão herbáceo, é uma alternativa viável em se tratando desta cultura, cujas partes não se destinam para o consumo humano (USEN et al., 2016 ; FIGUEIREDO et al., 2012). O objetivo deste estudo foi avaliar o efeito da utilização de águas residuárias, nas variáveis de crescimento, desenvolvimento e de produção do algodoeiro herbáceo (Gossipyum hirsutum. L).

\section{MATERIAL E MÉTODOS}

O experimento foi conduzido no período de 25 de setembro de 2012 a 08 de fevereiro de 2013, em condições de campo, na Estação Experimental de Tratamentos Biológicos de Esgotos Sanitários EXTRABES, no Município de Campina Grande, Estado da Paraíba, vinculado à Universidade Estadual da Paraíba - UEPB.

$\mathrm{O}$ local do experimento apresentou as seguintes coordenadas geográficas do local $07^{\circ} 15^{\prime} 18^{\prime \prime}$ de latitude sul e $35^{\circ} 52^{\prime} 28^{\prime \prime}$ 'de longitude oeste, a $550 \mathrm{~m}$ acima do nível do mar, na Microrregião do Agreste Central do Planalto da Borborema.

O clima da região onde se realizou o experimento, de acordo com a classificação climática de Köppen, é do tipo "CSa", que representa um clima mesotérmico, subsumido, com verão quente e seco (4 a 5 meses) e chuvas de outono e inverno. O período chuvoso é de março a junho e o mais seco é de outubro a dezembro.

Os dados meteorológicos referentes ao período de cultivo e coleta dos dados estão apresentados na tabela 1, foram coletados na estação climatológicaCNPA/EMBRAPA, referente ao período da pesquisa.

Tabela 1. Dados Meteorológicos

\begin{tabular}{lccccc}
\hline Mês/Ano & $\begin{array}{c}\text { Temperatura } \\
\text { Media }\left({ }^{\circ} \mathrm{C}\right)\end{array}$ & $\begin{array}{c}\text { Precipitação } \\
(\mathrm{mm})\end{array}$ & $\begin{array}{c}\text { Evapotranspiração } \\
\left(\text { ETo, mm mês }{ }^{-1}\right)\end{array}$ & $\begin{array}{c}\text { UR Média } \\
\text { do ar }(\%)\end{array}$ & Insolação Média (h) \\
\hline $09 / 2012$ & 22,5 & 6,2 & 139,5 & 74 & 8,2 \\
$10 / 2012$ & 23,0 & 10,2 & 158,3 & 74 & 8,0 \\
$11 / 2012$ & 24,1 & 0,5 & 156,1 & 43 & 10,9 \\
$12 / 2012$ & 24,5 & 9,2 & 197,2 & 72 & 8,3 \\
$01 / 2013$ & 26,9 & 27,2 & 212,3 & 72 & 7,9 \\
$02 / 2013$ & 25,0 & 30,1 & 178,7 & 7,9 \\
\hline
\end{tabular}

Umidade Relativa (UR); hora (h); temperatura ambiente

O solo utilizado foi coletado da camada superficial $(0-20 \mathrm{~cm})$, na Estação Experimental de Lagoa Seca, pertencente à Empresa Estadual de
Pesquisa Agropecuária da Paraíba - EMEPA - PB, no município de Lagoa Seca - PB. As amostras tiveram seus as análises físicas e químicas de seus 
atributos realizadas no Laboratório de Química e Fertilidade do Solo, no Centro de Ciências Agrárias da Universidade Federal da Paraíba (UFPB),
Campus II- Areia, PB. E os resultados são apresentados nas tabelas 2 e 3 .

Tabela 2. Características químicas do solo utilizado

\begin{tabular}{|c|c|c|c|c|c|c|c|c|c|}
\hline $\mathrm{pH}$ & $\mathrm{P}$ & $\mathrm{K}^{+}$ & $\mathrm{Na}$ & $\mathrm{H}^{+}+\mathrm{Al}^{+3}$ & $\mathrm{Al}^{+3}$ & $\mathrm{Ca}^{+2}$ & CTC & SB & M.O \\
\hline $1: 2,5$ & \multicolumn{2}{|c|}{$\mathrm{Mg} / \mathrm{dm}^{3}$} & & \multicolumn{5}{|c|}{ Cmolc/dm ${ }^{3}$} & $\mathrm{~g} / \mathrm{dm}^{3}$ \\
\hline 6,39 & 87,00 & 105,60 & 0,31 & 0,00 & 0,00 & 1,50 & 4,17 & 3,18 & 5,34 \\
\hline
\end{tabular}

Tabela 3. Características físicas do solo utilizado.

\begin{tabular}{|c|c|c|c|c|c|c|}
\hline \multicolumn{3}{|c|}{$\begin{array}{l}\text { Granulometria } \\
\text { g. } \mathrm{kg}^{-1}\end{array}$} & \multirow[t]{2}{*}{ Textura } & \multirow{2}{*}{\multicolumn{2}{|c|}{ 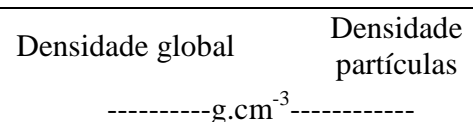 }} & \multirow{2}{*}{$\begin{array}{c}\text { Porosidade total } \\
\%\end{array}$} \\
\hline Areia & Silte & Argila & & & & \\
\hline 834 & 111 & 55 & Arenosa & 1,59 & 2,65 & 40 \\
\hline
\end{tabular}

\begin{tabular}{|c|c|c|c|c|c|}
\hline Parâmetros & $\mathbf{A A}$ & UASB & FS & $\mathbf{L M}$ & FA \\
\hline $\operatorname{DBO}\left(\mathrm{O}_{2} \mathrm{mg} \mathrm{L}^{-1}\right)$ & - & 125,13 & 83,75 & 69,16 & 104,14 \\
\hline $\operatorname{DQO}\left(\mathrm{O}_{2} \mathrm{mg} \mathrm{L}^{-1}\right)$ & - & 314,69 & 88,27 & 111,2 & 100,00 \\
\hline Fósforo Total (P mgL $\left.{ }^{-1}\right)$ & - & 6,52 & 6,56 & 5,55 & 5,90 \\
\hline Ortofosfato $\left(\mathrm{P}-\mathrm{PO}_{4-} \mathrm{mg} \mathrm{L}^{-1}\right)$ & - & 5,57 & 5,96 & 4,37 & 6,00 \\
\hline Nitrito $\left(\mathrm{NO}_{2}^{-} \mathrm{mg} \mathrm{L}^{-1}\right)$ & - & - & 0,28 & 0,77 & - \\
\hline Nitrato $\left(\mathrm{NO}_{3}^{-} \cdot \mathrm{mgL}^{-1}\right)$ & Ausente & - & 48,26 & 51,12 & - \\
\hline NTK (NTK. mgL ${ }^{-1}$ ) & - & 56,85 & 1,70 & 2,27 & 52,67 \\
\hline N. Amoniacal (N-NH$\left.{ }_{4}^{+} \cdot \mathrm{mg} \mathrm{L}^{-1}\right)$ & Ausente & 52,65 & 0,99 & 0,94 & 48,00 \\
\hline $\mathrm{pH}$ & 7,3 & 7,12 & 5,00 & 7,86 & 7,6 \\
\hline Alcalinidade total $\left(\mathrm{CaCO}_{3} \cdot \mathrm{mg} \mathrm{L}^{-1}\right)$ & 76,14 & 413,70 & 22,91 & 34,88 & 344,34 \\
\hline
\end{tabular}

AA- água de abastecimento; UASB - efluente de manta de lodo; LM - efluente de lagoas macrófitas; FS - efluente do filtro em serie; FA - efluente de filtro anaeróbio.

As amostras de solo foram acondicionadas em vasos plásticos com capacidade de $30 \mathrm{~L}$, sobre uma camada de $3 \mathrm{~cm}$ de brita em sua base, para facilitar a drenagem do excesso de água e evitar a perda de solo pelo aberturas existentes em cada vaso, em seguida realizou-se uma adubação orgânica com húmus (esterco de minhoca). A cultura utilizada na pesquisa foi o algodão herbáceo (Gossypium hirsutum L), cultivar BRS TOPÁZIO, sendo semeadas seis sementes em cada vaso, com $3 \mathrm{~cm}$ de profundidade e durante o período compreendido entre a semeadura e a germinação manteve-se o solo próximo da capacidade de campo, ocorrendo à germinação total sete dias após o plantio. Quinze dias após a germinação realizou-se o desbaste, deixando apenas uma planta por vaso.

$\mathrm{O}$ estudo foi realizado em delineamento experimental inteiramente casualizado com cinco tratamentos e quatro repetições. Com um total de 25 unidades experimentais. Inicialmente todas as parcelas foram uniformemente irrigadas com água de abastecimento até a germinação total, a partir daí a irrigação foi realizada de acordo com os seguintes tratamentos: tratamento 1 (T1) - irrigação com água de abastecimento proveniente da CAGEPA; tratamento 2 (T2) - irrigação com o efluente proveniente do reator UASB; tratamento 3 (T3) irrigação com efluente proveniente do filtro em série; tratamento 4 (T4) - irrigação com o efluente 
proveniente do filtro anaeróbio; e tratamento 5 (T5) - irrigação com o efluente proveniente da lagoa de macrófitos.

Foram realizadas capinas manuais para manter as plantas sempre livres de ervas daninhas, evitando assim a concorrência por nutrientes e luz, principalmente na fase inicial da cultura do algodão e também para facilitar a realização dos tratamentos e condução do experimento.

Os parâmetros avaliados foram: comprimento da folha, diâmetro de caule, altura de planta, número de folhas, produção do algodão em caroço e em pluma, número de frutos e capulhos, peso de sementes e matéria seca da parte aérea.

\section{RESULTADOS}

A análise de variância para as variáveis de crescimento da área foliar, diâmetro caulinar, altura de plantas e número de folhas, onde se verifica que houve efeito significativo nos tratamentos, onde analisou-se a área foliar e número de folhas e que não houve efeito significativo nas variáveis do diâmetro caulinar e altura de plantas.

$\mathrm{Na}$ tabela 5 estão apresentados os resultados dos parâmetros de crescimento, onde verifica-se que os tratamentos irrigados com água residuária tratada (UASB e Lagoas de Macrófitas), diferenciam-se estatisticamente pelo teste Tukey a $5 \%$ de probabilidade dos demais tratamentos nas variáveis
Para determinação da área foliar (AF), utilizou-se a seguinte equação:

$$
Y=0,7254 X^{2,08922} \quad \text { (Equação 1) }
$$

Proposta por Carter, Grimes (1969) e adaptada por Fideles Filho et al. (2010), para cultura de algodão de ciclo curto. Onde os valores de Y corresponde à área foliar (AF) e $\mathrm{X}$ ao comprimento da nervura principal da folha. As avaliações foram realizadas quinzenalmente, iniciando-se 23 dias após a emergência (DAE).

Os resultados foram submetidos à análise de variância, através do teste $\mathbf{F}$, e a comparação das médias pelo teste Tukey a 5\% de probabilidade, utilizando-se o software SAS 9.3.1 Portable. da área foliar e número de folhas, alcançando valores superiores nas demais variáveis.

\section{Área foliar}

A maior área foliar das plantas foi observada em plantas irrigadas com efluente proveniente de lagoas de macrófitos (FM), seguido do tratamento irrigado com efluente proveniente do reator (UASB), onde esses dois tratamentos diferiram apenas da água de abastecimento (AA). Já o tratamento irrigado com AA, que apresentou menores valores de foliar, foram semelhantes as obtidas com efluente filtrado em série (FS) e anaeróbico (FA). Com relação aos para os parâmetros diâmetro e altura das plantas, estes não apresentaram diferenças entre $\mathrm{AA}$ e todos os efluentes tratados (Tabela 5).

Tabela 5. Crescimento obtidos para a área foliar, diâmetro do caule, altura de plantas, em plantas de algodão cultivar BRS Topázio, em função dos diferentes tipos de água residuária tratada utilizadas na irrigação.

\begin{tabular}{lccc}
\hline Tratamento & Área Foliar & $\begin{array}{c}\text { Diâmetro do } \\
\text { caule }\end{array}$ & Altura da planta \\
\hline Água de abastecimento (AA) & $\mathrm{cm}^{2}$ & $\mathrm{~mm}$ & $\mathrm{~cm}$ \\
Manta de lodo (UASB) & $941,25 \mathrm{~b}$ & $4,94 \mathrm{a}$ & $34,44 \mathrm{a}$ \\
Filtro em série (FS) & $1170,19 \mathrm{a}$ & $4,97 \mathrm{a}$ & $38,44 \mathrm{a}$ \\
Filtro Anaeróbio (FA) & $1092,12 \mathrm{ab}$ & $4,84 \mathrm{a}$ & $34,56 \mathrm{a}$ \\
Lagoas de Macrófitos (FM) & $1105,16 \mathrm{ab}$ & $5,00 \mathrm{a}$ & $33,97 \mathrm{a}$ \\
\hline \multicolumn{2}{l}{ Medias seguida da mesma letra dentro da mesma coluna, não diferem entre si, pelo teste de Tukey a 5\% de probabilidade }
\end{tabular}

A variação da área foliar em relação aos dias após a semeadura (DAS), para os tratamentos irrigados com AA, efluente UASB, FS, FA, FM, está apresentado na figura 1 . Observa-se que o período com maior taxa de crescimento dos 30 aos 75 DAS que corresponde às fases II (desenvolvimento vegetativo) e a fase III (floração e frutificação), a partir dos 75 DAS os UASB e FM contribuíram para o desenvolvimento da massa foliar, resultando na ocorrência de maiores áreas foliares, ultrapassando os demais tratamentos. É provável que, devido aos nutrientes, tais como: fosforo, nitrogênio, potássio, provenientes das águas residuárias desses dois tratamentos disponibilizados para as plantas.

A área foliar é um importante fator de produção de uma cultura, visto ser a principal causa da intercepção da luz solar. Quanto mais rápido a cultura atingir a área foliar máxima, e quanto mais tempo a área foliar permanecer ativa, maior será a produção. Santos et al. (2006), utilizando a fertirrigação na cultura do quiabo, também obteve os melhores resultados da área foliar no tratamento irrigado com água residuária tratada proveniente do efluente UASB. 


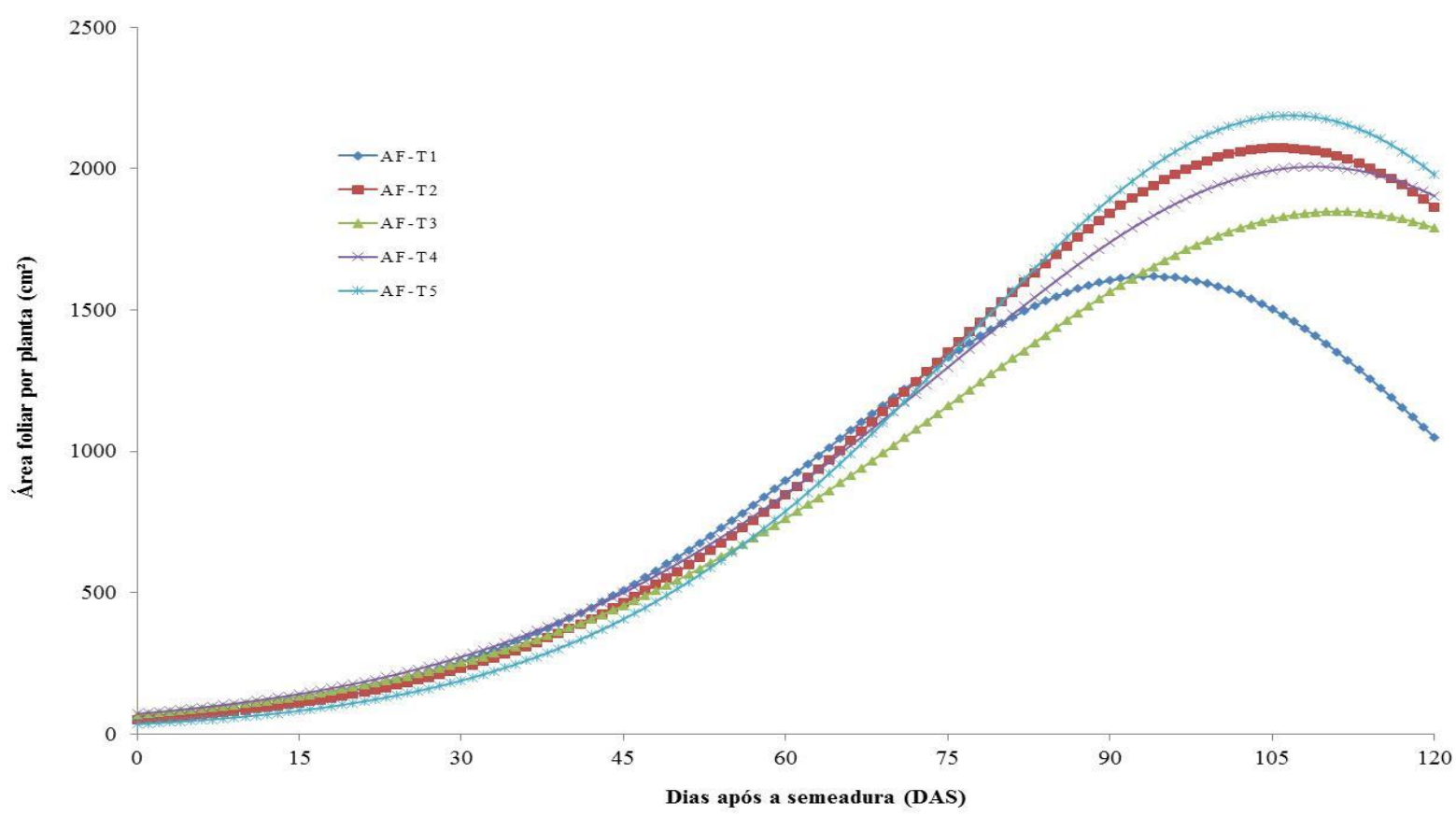

Figura 1. Área foliar em função dos dias após a semeadura da cultura de algodão irrigado com diferentes tipos de água residuária e abastecimento.

\section{Produção do algodão em caroço}

Na tabela 6, estão apresentados os resultados de produção do algodão em caroço. Observa-se que o parâmetro peso de sementes foi o único que diferiu entre os parâmetros avaliados. Com diferença significativa apenas para essa produção entre águas oriundas de AA e USDA, onde esta ultima foi superior. Embora o uso dos demais efluentes tenham sido sempre superiores ao uso da AA.

Tabela 6. Produção obtidas para o número de capulhos (NCAP), Peso da pluma (PLUMA) peso das sementes (PSEM)), produção (PRODUT) e massa seca da parte aérea (MSPA) em função dos diferentes tipos de água residuária de efluente de esgoto doméstico.

\begin{tabular}{lccccc}
\hline Tratamento & NCAP & PLUMA & PRODUT & PSEM & MSPA \\
\hline & $\mathrm{n}^{\mathbf{0}}$ planta $^{-1}$ & & & g planta $^{-1}$ & \\
\hline Água de abastecimento (AA) & $6,50 \mathrm{a}$ & $13.71 \mathrm{a}$ & $29.64 \mathrm{a}$ & $15.94 \mathrm{~b}$ & $26.50 \mathrm{a}$ \\
Manta de lodo (UASB) & $8,00 \mathrm{a}$ & $17.68 \mathrm{a}$ & $40.24 \mathrm{a}$ & $22.56 \mathrm{a}$ & $30.36 \mathrm{a}$ \\
Filtro intermitente (FS) & $7,25 \mathrm{a}$ & $14.88 \mathrm{a}$ & $32.96 \mathrm{a}$ & $18.08 \mathrm{ab}$ & $27.31 \mathrm{a}$ \\
Filtro Anaeróbio (FA) & $7,50 \mathrm{a}$ & $16.63 \mathrm{a}$ & $37.28 \mathrm{a}$ & $20.65 \mathrm{ab}$ & $31.42 \mathrm{a}$ \\
Lagoas de Macrófitos (FM) & $7,25 \mathrm{a}$ & $16.28 \mathrm{a}$ & $35.57 \mathrm{a}$ & $19.29 \mathrm{ab}$ & $29.97 \mathrm{a}$ \\
\hline
\end{tabular}

Em cada coluna medias seguidas de mesma letra não diferem entre si a nível de 5\% de probabilidade do teste de Tukey

A maior produção obtida pelos tratamentos irrigados com efluente de esgoto está de acordo com os resultados observados por Urbano et al. (2017) que, utilizando esgoto tratado na cultura da alface,

\section{Matéria seca por planta}

A variação da matéria seca da parte aérea do algodoeiro está relacionada nos tratamento T1 a T5 está apresentada na Figura 2, onde se observa que a matéria seca da parte aérea foi maior nos tratamentos que utilizaram água residuária tratada, destacando-se o Tratamento T4 (filtro anaeróbio), verificaram ganhos de produção, com o incremento de nutrientes ao solo. Evidenciando, assim, que a utilização de esgotos tratados em irrigação proporciona benefícios para as culturas.

com valor médio de 31,42 g/planta de matéria seca, enquanto que, o tratamento T1(irrigado com água de abastecimento) foi de 26,50 g/planta, apresentando os menores valores, onde não se observou diferenças significativas entre os tratamentos analisados.

Elfanssi et al. (2018) observaram que a água de esgoto doméstico tratada pode ser utilizada para o cultivo da alfafa, proporcionando bons resultados, proporcionada pela quantidade de nutrientes 
encontradas nesses efluentes, melhorando as propriedades físico-químicas e a fertilidade do solo em relação ao poço de água e aumenta a produção. Já Abdoulkader et al. (2015), verificaram que a irrigação com águas de esgotos sanitários tratadas obteve indicadores positivos sobre o crescimento e produção das mudas de Panicum maximum.

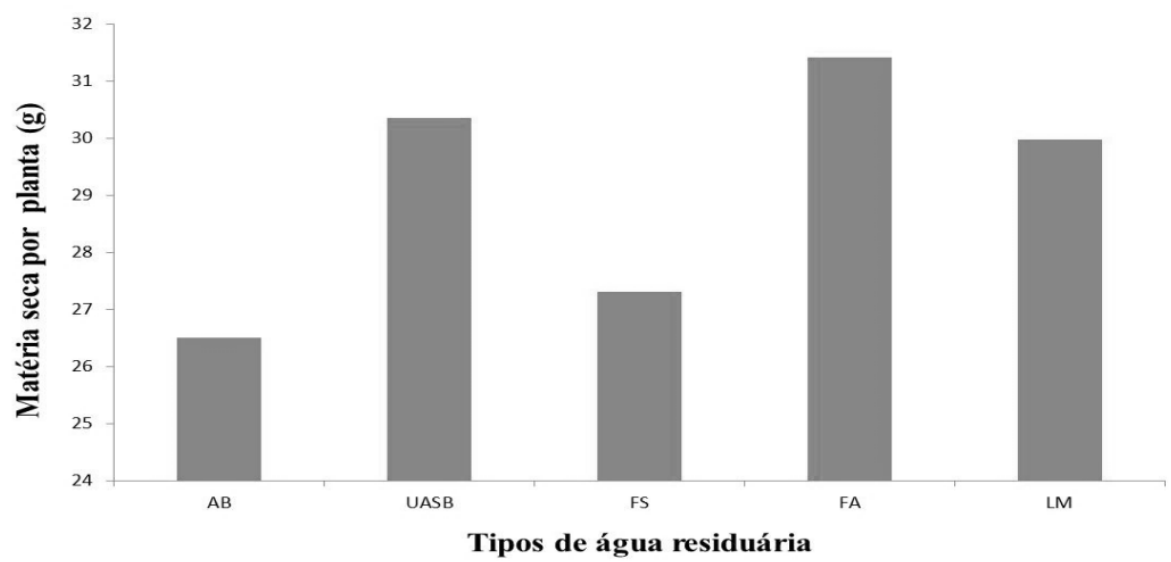

Figura 2. Materia seca da parte aerea do algodoeiro em função dos diferentes tipos de água residuária e abastecimento

\section{Peso de sementes por planta}

Na Figura 3 estão apresentados os dados do peso de sementes por planta do algodoeiro, em relação aos diferentes tipos de águas residuárias e abastecimento. Verifica-se que a variável peso de sementes por planta do algodoeiro apresentou melhor resultado no tratamento irrigado com efluente proveniente de reator UASB, alcançando um valor médio de 22,56gramas/planta, onde diferiu estatisticamente para os demais tratamentos. Já o tratamento irrigado com água de abastecimento foi o que obteve os menores valores com 15,94 gramas/planta. Corroborando com Gatta et al. (2016), onde os tratamentos irrigados com água residuaria tratada na cultura da alcachofra, afetaram significativamnete o total de cabeças comercializáveis, em termos de número e peso por hectare, com maior rendimento do que o obtido com irrigação com água de poço, além disso, dentro das classes principais, a produção de cabeças principais foi melhorada pela aplicacão das águas residuais, aumentando em 57\%, em comparação com á agua de poço. Ben et al. (2018), Urbano et al. (2017) verificaram que a produção e os valores das demais variáveis alcançados com a irrigação com apenas o efluente foram equivalentes à irrigação com água do poço mais adubação química, comprovando a possibilidade da utilização apenas do esgoto tratado sem adubação, proporcionando economia de fertilizante e principalmente água.

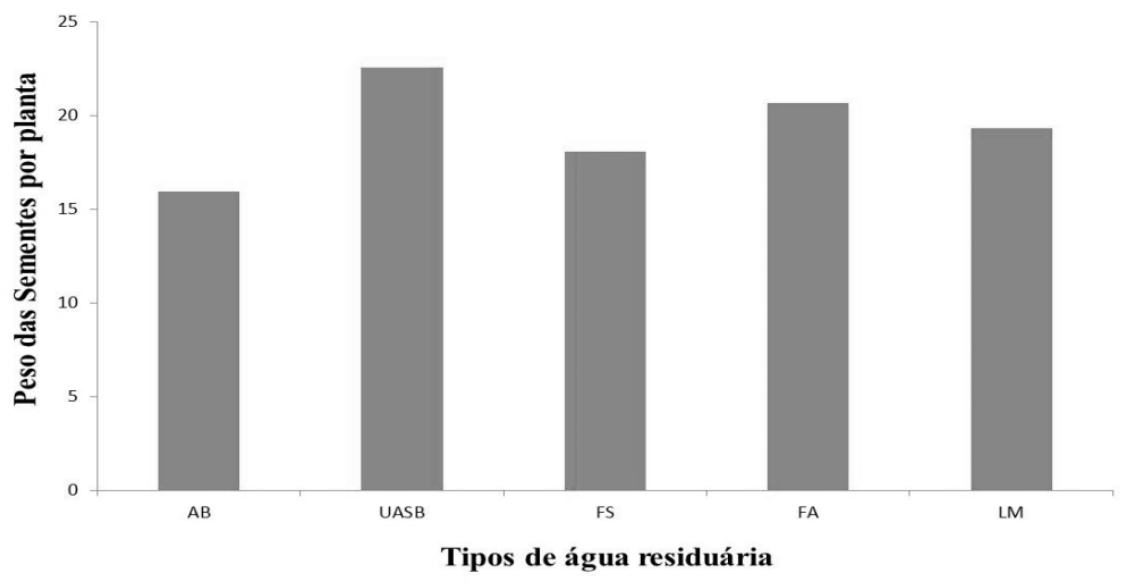

Figura 3. Peso de sementes por planta do algodoeiro em função dos diferentes tipos de água residuária e abastecimento. 


\section{CONCLUSÃO}

A irrigação com água residuária oriunda de USDA promoveu aumento da área foliar e peso de sementes da cultura do algodão. Os resultados obtidos neste estudo ressaltam a importância de considerar a água residuária como uma forma alternativa de irrigação em culturas que não são empregadas para a alimentação humana, sobretudo na região semiárida onde a limitação hídrica é uma realidade a qual o agricultor familiar deve adequar os seus sistemas de produção.

\section{AGRADECIMENTOS}

Os autores gostariam de agradecer ao Dr. Flávio Carmo pela excelente revisão, sugestões e contribuições ao nosso manuscrito. Ao Dr. Tancredo Souza pelas recomendações e apontamento realizados ao longo da disciplina de Metodologia da Pesquisa Científica que também foram fundamentais para a conclusão deste artigo. E a CAPES (Coordenação de Aperfeiçoamento de Pessoal de Nível Superior - Brasil) pela concessão da bolsa PNPD (Código de financiamento 001) do segundo autor.

\section{REFERÊNCIAS}

ABDOULKADER, B. A., MOHAMED, B., NABIL, M., ALAOUI-SOSSÉ, B., ERIC, C., ALEYA, L. Wastewater use in agriculture in Djibouti: Effectiveness of sand filtration treatments and impact of wastewater irrigation on growth and yield of Panicum maximum. Ecological Engineering, vol. 84, p. 607-614, 2015.

BARBOSA, B., COSTA, J., FERNANDO, A. L., PAPAZOGLOU, E. G. Wastewater reuse for fiber crops cultivation as a strategy to mitigate desertification. Industrial Crops and Products, vol. 68, p. 17-23, 2015.

BEDBABIS, S., TRIGUI, D., BEN AHMED, C., CLODOVEO, M. L., CAMPOSEO, S., VIVALDI, G. A., BEN ROUINA, B. Long-terms effects of irrigation with treated municipal wastewater on soil, yield and olive oil quality. Agricultural Water Management, vol. 160, p. 14-21, 2015.

BEN, A., ZOUARI, M., TRABELSI, L., KHABOU, W., ZOUARI, N. Physiological improvements of young olive tree ( Olea europaea L . cv . Chetoui ) under short term irrigation with treated wastewater. Agricultural Water Management, v. 207, p. 53-58, 2018.

CHOWDHURY, S., AL-ZAHRANI, M. FUZZY. Synthetic evaluation of treated wastewater reuse for agriculture. Environment, Development and Sustainability, vol. 16, n. 3, p. 521-538, 2014.
ELFANSSI, S., OUAZZANI, N., MANDI, L. Soil properties and agro-physiological responses of alfalfa (Medicago sativa L.) irrigated by treated domestic wastewater. Agricultural Water Management, vol. 202, p. 231-240, 2018.

EL MOUSSAOUI, T., WAHBI, S., MANDI, L., MASI, S., OUAZZANI, N. Reuse study of sustainable wastewater in agroforestry domain of Marrakesh city. Journal of the Saudi Society of Agricultural Sciences, p. 1-6, 2017.

FIDELES FILHO, J., BELTRÃO, N. E. de. M., PEREIRA, A. S. Desenvolvimento de uma régua para medidas de área foliar do algodoeiro. Revista Brasileira de Engenharia Agrícola e Ambiental, v.14, n.7, p.736$741,2010$.

FIGUEIREDO, A. M. F. de., MELO, A. A. de., AZEVEDO, C. A. V. de., LIMA, V. L. A. de.; DANTAS NETO, J., PINHEIRO, I. de. F. S. Crescimento e produção de algodão colorido com água residuária doméstica tratada e composto orgânico. Revista Educação Agrícola Superior, v.27, n.1, p.19-24, 2012.

GANJEGUNTEA, G., APRIL, G. N, YANQI, W. Effects of treated municipal wastewater irrigation on soil properties, switchgrass biomass production and quality under arid climate [Periódico] // Industrial Crops and Products, vol. 99, p. 60-69, 2017.

GARCIA, X., PARGAMENT, D. Reusing wastewater to cope with water scarcity: Economic, social and environmental considerations for decision-making. Resources, Conservation and Recycling, vol. 101, p. 154-166, 2015.

GATTA, G., LIBUTTIA, A., BENEDUCEA, L., GAGLIARDIA, A., DISCIGLIOA, G., LONIGROB, A., TARANTINO, E. Reuse of treated municipal wastewater for globe artichoke irrigation: Assessment of effects on morpho-quantitative parameters and microbial safety of yield. Scientia Horticulturae, vol. 213, p. 55-65, 2016.

GRIMES, D. W., CARTER, L. M. A linear rule for direct nondestructive leaf área measurements. Agronomy Journal, v.3, n.61, p.477-479, 1969.

INTRIAGO, J. C., LÓPEZ-GÁLVEZ, F., ALLENDE, A., VIVALDI, G. A., CAMPOSEO, S., NICOLÁS, E., ALARCÓN, J. J., SALCEDO, F. P. Agricultural reuse of municipal wastewater through an integral water reclamation management. Journal of Environmental Management, v. 203, p. 135-141, 2018.

JEONG, H., KIM, H., JANG, T., PARK, S. Assessing the effects of indirect wastewater reuse on paddy irrigation in the Osan River watershed in Korea using the SWAT model. Agricultural Water Management, vol. 163, p. 393-402, 2016. 
JUANICÓ, M. Reutilización de águas residuales. Qué se puede aprender de la experiencia israelí. Revista Tecnologia Del Água, n.285, p.58-67. 2007.

SAID INES, B., MUSCOLO, A. Effects of Irrigations with Treated Municipal Wastewater on Phenological Parameters of Tetraploid Cenchrus ciliaris L. Journal of Food Processing \& Technology, vol. 07,n. 02, p. 2-5, 2016.

SANTOS, K. D., HENRIQUE, I. N., SOUSA, J. T. de., LEITE, V. D. Utilização de esgoto tratado na fertirrigação agrícola. Revista de biologia e ciências da terra, n.1, (Suplemento especial) 2006.

SOUSA NETO, O. N., ANDRADE FIHO, J., DIAS, N. S. de.; REBOUÇAS, J. R. L., OLIVEIRA, F. R. A. de., DINIZ, A. A. Fertirrigação do algodoeiro utilizando efluente doméstico tratado. Revista Brasileira de Engenharia Agrícola e Ambiental, v.16, n.2, p.200-208, 2012.

REZNIK, A., FEINERMAN, E., FINKELSHTAIN, I., FISHER, F., HUBER-LEE, A., JOYCE, B., KAN, I
Economic implications of agricultural reuse of treated wastewater in Israel: A statewide long-term perspective. Ecological Economics,v. 135, p. 222-233, 2017.

URBANO, V. R., MENDONÇA, T. G., BASTOS, R. G., SOUZA, C. F. Effects of treated wastewater irrigation on soil properties and lettuce yield. Agricultural Water Management, v. 181, p. 108-115, 2017.

UZEN, N., CETIN, O., UNLU, M. Effects of domestic wastewater treated by anaerobic stabilization on soil pollution, plant nutrition, and cotton crop yield. Environmental Monitoring and Assessment, vol. 188,n. 3, p. 1-11, 2016.

WIELEMAKER, C., WEIJMA, J., ZEEMAN, G. Harvest to harvest: Recovering nutrients with New Sanitation systems for reuse in Urban Agriculture. Resources, Conservation and Recycling, vol. 128, p. 426-437, 2018.

WOLTERSDORF, L., ZIMMERMANN, M., DEFFNER, J., GERLACH, M., LIEHR, S Benefits of an integrated water and nutrient reuse system for urban areas in semiarid developing countries. Resources, Conservation and Recycling, v. 128, p. 382-393, 2018. 